\section{Fibrina rica en plaquetas en la cicatrización de los tejidos periodontales}

\section{Platelet-rich fibrin in the healing of periodontal tissues}

\section{Resumen}

La fibrina rica en plaquetas (FRP) es una membrana o coágulo de fibrina que contiene leucocitos, plaquetas, citoquinas y factores de crecimiento; es considerado un biomaterial y concentrado plaquetario de segunda generación que se obtiene mediante la centrifugación de sangre del propio paciente. La presente revisión tiene como objetivo evaluar la cicatrización de los tejidos periodontales con la aplicación de la FRP. De la revisión se concluye que la FRP es una buena alternativa para promover una mejor cicatrización, además de potenciar otros biomateriales con el fin de condicionar una mejor regeneración y un menor periodo de tiempo.

Palabras clave: Fibrina rica en plaquetas; Cicatrización de heridas; Regeneración ósea (fuente: DeCS BIREME).

\begin{abstract}
Platelet-rich fibrin (FRP) is a fibrin membrane or clot that contains leukocytes, platelets, cytokines and growth factors; it is considered a biomaterial and second generation platelet concentrate that is obtained by centrifuging the patient's own blood. This review aims to evaluate the healing of periodontal tissues with the application of FRP. The review concludes that FRP is a good alternative to promote better healing, in addition to promoting other biomaterials in order to condition a better regeneration and a shorter period of time.
\end{abstract}

Keywords: Platelet-rich fibrin; Wound healing; Bone regeneration (source: MeSH NLM).

\section{Artículo de Revisión}

Eduardo López-Pagán ${ }^{1, a, b}$, Ana Cecilia Pascual-Serna ${ }^{1, a, c}$

${ }^{1}$ Universidad Nacional Daniel Alcides Carrión, Facultad de Odontología. Pasco, Perú.

a Cirujano Dentista.

${ }^{\mathrm{b}}$ Especialista en Periodoncia.

${ }^{c}$ Magíster en Odontología.

\section{Correspondencia:}

Eduardo López Pagán: elopezp@undac.edu.pe Av. Daniel Alcides Carrión N 110, Urbanización San Juan, Yanacancha. Pasco. Perú. Código postal: 19001. ORCID: 0000-0002-3997-0050

\section{Coautora:}

Ana Cecilia Pascual Serna: ceciliapascuals@hotmail.com ORCID: 0000-0002-2556-5142

\section{Editor:}

Juan Carlos Cuevas-González

Universidad Autónoma de Ciudad Juárez, México.

Conflicto de intereses: los autores declaran no tener conflictos de interés.

Fuente de financiamiento: autofinanciado

Recibido: 07/10/19

Aceptado: 25/11/19

Publicado: 24/02/20 


\section{Introducción}

La regeneración o reparación de un tejido se concreta a través de un proceso de cicatrización, cuando la estructura y función de esos tejidos no son completamente renovados estamos frente a la formación de un tejido cicatrizal conocido como reparación, pero si la arquitectura y función se completó con un tejido igual al existente previo a la injuria se condiciona una regeneración ${ }^{1}$.

La cicatrización constituye una respuesta básica en los seres vivientes $y$, en el cual se condiciona el restablecimiento satisfactorio de la integridad de los tejidos. La cicatrización no es un fenómeno aislado, sino constituye un proceso condicionado por factores bioquímicos, cambios en las estructuras tisulares que finalmente determinan la formación de la cicatriz ${ }^{2}$.

El tratamiento de la enfermedad periodontal, tanto quirúrgico como no quirúrgico, da lugar a que los tejidos periodontales ingresen a un proceso de reparación, los cuales pueden condicionar alguna incomodidad en el paciente sobre todo después del tratamiento quirúrgico periodontal ${ }^{3}$. Por consiguiente, un gran número de investigadores se han abocado a la búsqueda de nuevas terapias que condicionen una mejor cicatrización y disminuyan el trauma post-operatorio. Los materiales bioactivos de origen autólogo como concentrados plaquetarios ricos en factores de crecimiento se han presentado como una alternativa terapéutica periodontal ${ }^{4}$, pues de estos se ha comprobado que estimulan la proliferación y diferenciación celular disminuyendo el tiempo de cicatrización ${ }^{4,5}$.

La FRP es un material de regeneración que contiene gran cantidad de factores de crecimiento, leucocitos, plaquetas y citoquinas que son necesarios para la cicatrización; $y$ todos estos constituyentes se recogen en una sola membrana o matriz de fibrina. Su uso en Odontología es amplia, fundamentalmente en las especialidades de: cirugía buco maxilofacial, implantología oral y en particular en periodoncia es actualmente una tendencia de mucho interés ${ }^{6-8}$.

\section{Revisión de literatura}

Las enfermedades bucales como la caries dental y la enfermedad periodontal son dos de los problemas más significativos de la Salud Pública Bucal ${ }^{9}$. La enfermedad periodontal si no se trata puede llegar a condicionar la pérdida de dientes por la afectación de los tejidos periodontales; cuando la lesión del periodonto es considerable el tratamiento debe ser quirúrgico, generalmente cuando se mantienen bolsas $\geq$ a $6 \mathrm{~mm}^{10}$.

La terapia básica periodontal es muy importante para poder disminuir las condiciones de afectación de los tejidos periodontales, luego de una reevaluación se determinará el pase o no a una terapia quirúrgica ${ }^{10,11}$.

El tratamiento quirúrgico de la enfermedad periodontal cumple esencialmente dos propósitos: el primero, crea la accesibilidad y visibilidad para un correcto desbridamiento de las superficies radiculares afectadas; el segundo, establece una morfología gingival que facilita la higiene y el autocontrol de los depósitos dentarios mejorando la preservación de los dientes a largo plazo ${ }^{11}$.

\section{Proceso de cicatrización}

Cuando se realiza el tratamiento periodontal de terapia básica o quirúrgica se desencadena un proceso de cicatrización ${ }^{1,12}$. El proceso de cicatrización ocurre para reponer la estructura de los tejidos lesionados. Se considera como un proceso biológico, complejo y como respuesta del organismo frente a un agente lesivo ${ }^{13}$.

La primera fase coagulación, se suscita inmediatamente después de la lesión y dura aproximadamente 15 minutos ${ }^{14}$, esta se inicia con la adherencia y agregación plaquetaria en conjunción al daño vascular y tisular provocando que se forme un tapón plaquetario, posteriormente un coágulo, con lo cual se consolida la hemostasia y la activación de factores de crecimiento inmersos en el proceso de cicatrización, donde las plaquetas juegan un rol primordial ${ }^{4,5}$, consecutivamente se desarrollan las siguientes fases: inflamación, proliferación y remodelación/maduración ${ }^{15}$.

La fase inflamatoria, tiene su inicio hacia el minuto 16 y presenta una duración de hasta seis días ${ }^{14}$, se presenta como respuesta protectora e intenta desaparecer o aislar los agentes que estén condicionando una lesión ${ }^{3}$. Su objetivo es proporcionar una rápida hemostasia y comenzar una secuencia de reacciones que lleven a la regeneración del tejido. Cuando hay una lesión la sangre sale de los vasos, se forma un hematoma llenando el espacio tisular con plaquetas. Los factores de crecimiento y las citoquinas son liberadas fundamentalmente por las plaquetas y otras células, condicionando que las células migren, proliferen y se diferencien y así como también en la síntesis de matriz extracelular. El soporte del espacio regenerativo y se permita la migración y proliferación de las células está dado por la red de fibrina del hematoma que funciona como una matriz provisional ${ }^{5,15}$.

La fase de proliferación, es una fase contundente en la cicatrización y se inicia hacia el tercer día y dura aproximadamente de 15 a 20 días ${ }^{14}$. El tejido necrosado se elimina y se reemplaza por un nuevo tejido vivo, que debe ser específico de su entorno celular (tejido fibroso, cartilaginoso o hueso). La diferenciación se lleva a cabo por las células madre condicionando condrocitos, fibroblastos u osteoblastos y otras células en relación al tipo de tejido que se debe regenerar. La diferenciación celular se condiciona por: los factores de crecimiento y citoquinas, las hormonas, los nutrientes, el $\mathrm{pH}$, la presión parcial de oxígeno, el entorno mecánico y eléctrico local ${ }^{5,15}$.

La fase final de remodelación/maduración, dura aproximadamente entre uno a dos años ${ }^{14} \mathrm{y}$ se caracteriza por la formación de un tejido que intenta un máximo parecido al original. En los cambios que se producen hay una disminución en la densidad y vascularidad celular, el exceso de la matriz que se repara es eliminado y 
las fibras colágenas se orientan hacia las líneas de mayor tensión de la matriz reparada ${ }^{5,15}$.

La cicatrización de los tejidos blandos y duros tiene lugar a partir de una serie de eventos que a nivel celular y ultraestructural son regulados por las proteínas ${ }^{4}$, la función de las plaquetas es destacable en la hemostasia, pero también en el proceso de reparación de una herida ${ }^{16}$. Las plaquetas son atraídas hacia el lugar de la lesión, la formación de fibrina y la cascada de coagulación son estimuladas ${ }^{17}$. Los factores de crecimiento están presentes en cada una de las fases de cicatrización; promoviendo en la zona de lesión la inducción de la quimiotaxis, la angiogénesis y osteogénesis, la proliferación y diferenciación de células progenitoras, la división celular y la síntesis de colágeno. Por lo tanto, con la intensión de mejorar la calidad del coágulo y la cicatrización se ha buscado nuevas alternativas como los concentrados plaquetarios ${ }^{18}$.

\section{Concentrados plaquetarios}

Los concentrados plaquetarios son biomateriales autógenos obtenidos por centrifugación sanguínea a un determinado tiempo y revoluciones, consecuentemente de dicho procedimiento se separan las plaquetas. En las últimas dos décadas, se comprendió mejor las propiedades fisiológicas de las plaquetas en la cicatrización de las heridas, lo que ha llevado a masificar sus aplicaciones terapéuticas en diferentes formas como resultado de citaféresis ${ }^{19}$.

Por consiguiente, los concentrados plaquetarios tienen una buena base científica y biológica que los respalda, considerándolas como una alternativa terapéutica a disposición. Estos concentrados son clasificadas como de: $1^{\circ}$ Generación - Plasma Rico en Plaquetas (PRP), el cual requiere de anticoagulante antes de la primera centrifugación y trombina bovina después de la segunda ${ }^{8,20}$, y de $2^{\circ}$
Generación - Fibrina Rica en Plaquetas (FRP), obtenida de la centrifugación y sin el uso de aditivos como anticoagulantes u otro agente gelificante ${ }^{8,21,22}$ (Figura 1).

Se ha comprobado que los concentrados plaquetarios son útiles para la regeneración ósea, la fijación de injertos, la hemostasia y la cicatrización de heridas, favoreciendo los tratamientos odontológicos en cirugía oral ${ }^{23}$, específicamente en implantología, cirugía maxilofacial y reconstructiva; también en los tratamientos periodontales y regenerativos cuando el periodonto ha sido afectado, formando un nuevo cemento, hueso alveolar y ligamento periodontal ${ }^{24}$.

\section{Fibrina rica en plaquetas}

La FRP es un concentrado plaquetario para mejorar la cicatrización de heridas y la inmunidad; biomaterial autólogo que incorpora en una matriz de fibrina leucocitos, citoquinas, plaquetas y factores de crecimiento ${ }^{22}$. La fibrina es una molécula activa de fibrinógeno plasmático ${ }^{25}$ que conjuntamente con las plaquetas ayudan y aceleran la hemostasia y cicatrización de los tejidos ${ }^{26}$.

El Dr. Grey Knighton en el 2015, fue el primero en usar fibrina de la sangre para el control de hemorragia en una cirugía cerebral ${ }^{27}$. Marx, en 1986, utilizó el plasma rico en plaquetas en cirugía maxilofacial así como Anitua, en $1999^{19}$. El Dr. Choukroun en el año 2000 propuso el protocolo de FRP para heridas que tardaban en cicatrizar y en el 2006 introdujo el uso de FRP para diferentes tratamientos odontológicos ${ }^{22}$.

Se han reportado varios protocolos de centrifugación basados en modificar el tiempo de 8 a 12 minutos y la velocidad de 2500 a $3200 \mathrm{rpm}$ generando diferentes resultados clínicos ${ }^{27}$, siendo el más utilizado de 2700 rpm durante 12 minutos a $280 \mathrm{G}$ (fuerza gravitacional del centrifugado) de acuerdo al protocolo recomendado por Choukroun ${ }^{8,20,22,28}$.

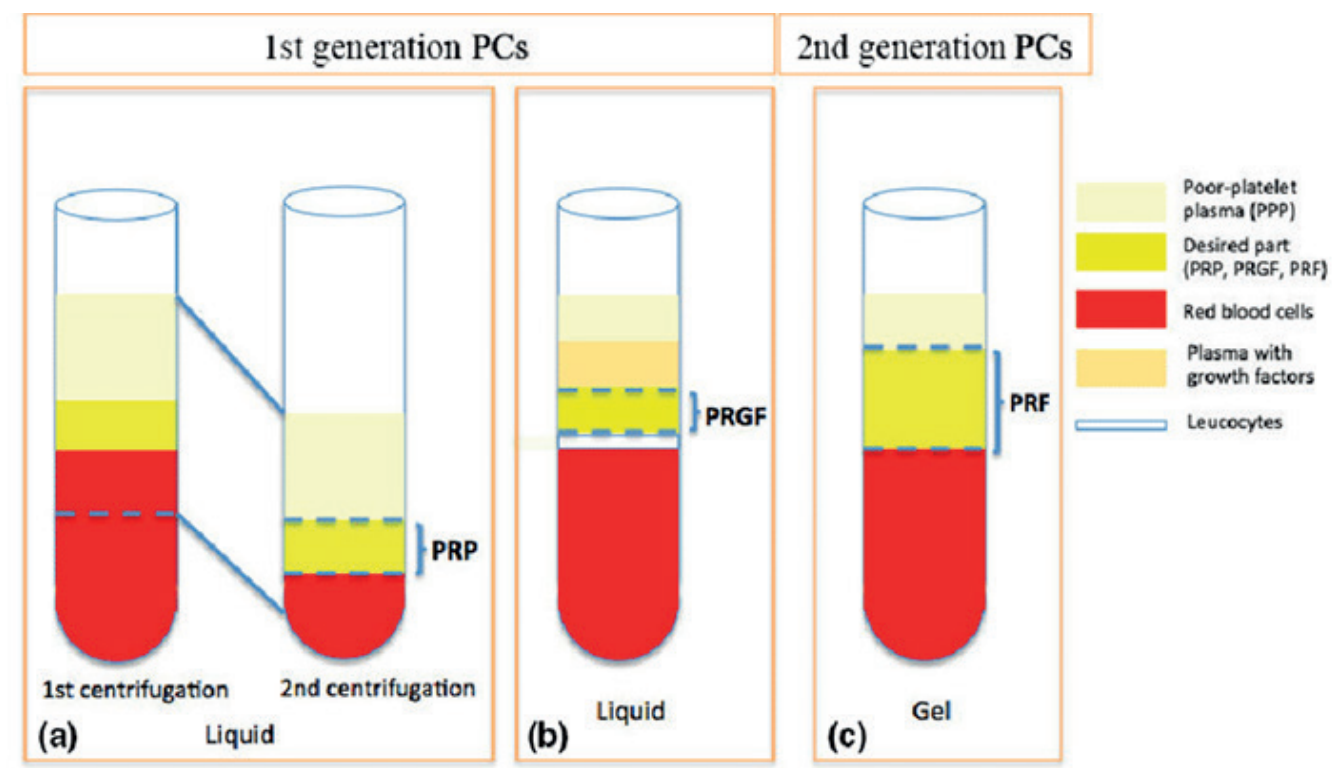

Figura 1. Concentrados plaquetarios: (a) PRP: plasma rico en plaquetas; (b) PRGF: plasma rico en factores de crecimiento; (c) PRF: Plasma rico en fibrina. Fuente ${ }^{45}$ 
El uso de PRF en la práctica clínica es sencilla, ya que para obtener este concentrado plaquetario se utiliza una técnica simple y rápida. También rentable para el paciente comparado con otras técnicas regenerativas; además hay menor probabilidad de contagio o que condicione alguna reacción alérgica o de rechazo. El PRF es un biomaterial vivo complejo, y debemos ser muy cuidadosos en la preparación y conservación del material. El éxito de esta técnica depende de la velocidad de recolección de la muestra de sangre venosa y de la transferencia para la centrifugación. La coagulación se dará casi de inmediato porque la muestra se mantiene completamente autóloga 29.

Analizando estudios originales con la aplicación de la FRP (Tabla) han demostrado su efectividad; podemos mencionar el de Tovar ${ }^{30}$ en su investigación denominada aplicación de fibrina rica en plaquetas en la cicatrización postexodoncias dentarias en pacientes con riesgo y con osteonecrosis maxilar inducida por bifosfonatos concluyó que el uso de FRP brinda una alternativa de cicatrización y regeneración ósea en estos pacientes; otro como Lobo ${ }^{31}$ realizó un estudio de evaluación clínica del tiempo de cicatrización de alvéolos post extracción aplicando distintas técnicas de cierre de heridas, dentro de ellas aplicando FRP y suturando comparados con otros como dejar el alveolo abierto, suturando el alveolo y aplicando gelatina hemostática y suturando, concluyó que el uso del PRF disminuye el tiempo de cicatrización de las heridas y genera una mayor disminución de la sensación de dolor comparado con las otras técnicas; Guzmán ${ }^{41}$ en su estudio sobre cicatrización de tejido óseo y gingival en cirugías de terceros molares inferiores donde comparó la cicatrización con la aplicación del PRF y la cicatrización fisiológica concluye que la cicatrización del tejido blando y duro mejora con el uso del PRF confirmando su efectividad; Vento ${ }^{32}$ en su estudio efecto clínico del plasma rico en fibrina como terapia conjunta a la fase quirúrgica en el tratamiento de la periodontitis crónica concluyó que el uso del plasma rico en fibrina mejoró significativamente las características clínicas gingivales, sangrado, inflamación, además de la reducción de la profundidad de sondaje y el nivel de inserción clínico comparada sin la aplicación de PRF; también Lobatón ${ }^{33}$ en su investigación sobre el efecto de la fibrina rica en plaquetas para la cicatrización de tejidos blandos post-exodoncia de terceros molares inferiores retenidos tuvo como resultado mejorías en cuanto al dolor, color, consistencia comparado con el lado control; García ${ }^{34}$ en su estudio: uso de PRF en preservación de reborde alveolar, concluyó que el uso de la PRF es una alternativa terapéutica para la preservación del reborde alveolar con fines de implantación temprana; así mismo Atamari et al. ${ }^{2}$ realizaron un estudio aplicando la FRP en el cierre clínico de la mucosa alveolar post-exodoncia en pacientes sometidos a cirugía bucal del cual concluyeron que la FRP sí beneficia el cierre clínico de la mucosa alveolar postexodoncia, disminuyendo los síntomas y complicaciones post quirúrgicas y acelerando la cicatrización comparado con el control; Quispe ${ }^{35}$ en su estudio efecto del uso de la fibrina rica en plaquetas, según el protocolo de Choukroun, como único material en la preservación del reborde alveolar postexodoncia y del cual concluye que la FRP condicionó una menor reabsorción horizontal y vertical en los rebordes alveolares postexodoncia tanto en la evaluación clínica y tomográfica, a los 2 meses de evaluación se obtuvo una mejor preservación de altura de reborde; Ochoa ${ }^{36}$ realizó un estudio de caso denominado proceso de cicatrización post exodoncia de los terceros molares mandibulares mediante la utilización de plasma rico en plaquetas, concluyendo que el PRP es eficiente en la regeneración de los tejidos en corto tiempo, donde no existen molestias postoperatorias como inflamación y dolor para el paciente.

\section{Cicatrización de los tejidos periodontales con PRF}

En el proceso de recuperar los tejidos periodontales perdidos se han buscado varias alternativas de regeneración; Ross et al. ${ }^{37}$ en 1974 introdujeron el concepto de potencial regenerativo de las plaquetas, al describir un factor de crecimiento a partir de plaquetas. Las plaquetas liberan factores de crecimiento que están inmersos en el interior de la matriz de fibrina después de su activación.

Los factores de crecimiento que se secretan como consecuencia de un injerto, herida o colgajo se unen a la superficie externa de la membrana celular de dicho tejido vía receptores transmembranales. Se ha demostrado mediante estudios que los fibroblastos, los osteoblastos, las células madre mesenquimatosas adultas, las células endoteliales y las células epidérmicas, expresan los receptores para los factores en su membrana celular. Estos receptores transmembranales activan una proteína que se dirige hacia el núcleo y se conoce como de señalización interna. En el núcleo, la proteína desbloquea la secuencia genética regular para que se desarrolle una función específica, tal como mitosis, síntesis de colágeno, formación de osteoides, etc. ${ }^{38}$.

Se ha demostrado que, los factores de crecimiento derivadas de las plaquetas tales como: PDGF (factor de crecimiento derivado de plaquetas), VEGF (factor de crecimiento endotelial vascular, TGF alfa (factor de crecimiento transformador alfa), EGF (factor de crecimiento epidérmico) y TGF - beta ( factor de crecimiento transformador beta) influyen en la cicatrización, (Figura 2) tienen como efecto biológico la viabilidad y proliferación de células osteoprogenitoras y preosteoblastos que habitan en los tejidos adyacentes (periostio, endostio). Las plaquetas, desempeñando un papel fundamental en la regeneración ósea y en la cicatrización de los tejidos blandos, particularmente en la cicatrización de heridas periodontales ${ }^{2,21,39}$.

Según Hernández et al. ${ }^{40}$ la utilización de fibrina autóloga en lesiones de evolución lenta e incierta condiciona un menor tiempo de recuperación, promoviendo una mejor cicatrización y calidad del tejido reparado con un alto grado de satisfacción. De igual modo Guzmán et al. ${ }^{41}$ determinaron que la cicatrización del tejido blando 
Tabla. Trabajos de investigación originales de cicatrización con la aplicación de fibrina rica en plaquetas (FRP)

\begin{tabular}{|c|c|c|c|c|}
\hline $\begin{array}{l}\text { Investigador } \\
\text { (res) }\end{array}$ & Diseño de estudio & Población & Intervención & Conclusiones \\
\hline $\begin{array}{l}\text { Tovar } \\
(2011)\end{array}$ & $\begin{array}{l}\text { Investigación expe- } \\
\text { rimental }\end{array}$ & 40 pacientes & $\begin{array}{l}\text { Evalúa la cicatrización y regeneración } \\
\text { de los tejidos, una vez aplicado la FRP y } \\
\text { la relación con el riesgo de presentación } \\
\text { y la presencia de ONM inducida por } \\
\text { Bifosfonato. }\end{array}$ & $\begin{array}{l}\text { Señala que el uso de FRP brinda una } \\
\text { alternativa de cicatrización y regeneración } \\
\text { ósea. }\end{array}$ \\
\hline $\begin{array}{l}\text { Lobo } \\
(2014)\end{array}$ & $\begin{array}{l}\text { Ensayo clínico } \\
\text { controlado }\end{array}$ & $\begin{array}{l}24 \text { alveolos } \\
\text { (06 pacientes) }\end{array}$ & $\begin{array}{l}\text { Cicatrización de cuatro unidades de } \\
\text { medida, un alveolo superior derecho de } \\
\text { control, superior izquierdo suturado, } \\
\text { inferior derecho acondicionado con PRF } \\
\text { y suturado, e inferior izquierdo acondi- } \\
\text { cionado con hemostático de Gelatina y } \\
\text { suturado. } \\
\text { Para controlar el dolor se evaluará según } \\
\text { la escala visual análoga (V.A.S.) }\end{array}$ & $\begin{array}{l}\text { La tendencia encontrada indica que el uso } \\
\text { del PRF disminuye el tiempo de cicatri- } \\
\text { zación de las heridas y genera una mayor } \\
\text { disminución de la sensación de dolor; } \\
\text { seguido por el uso del hemostático de ge- } \\
\text { latina y la seda, en el orden mencionado. }\end{array}$ \\
\hline $\begin{array}{l}\text { Guzmán G.F. } \\
(2017)\end{array}$ & $\begin{array}{l}\text { Estudio } \\
\text { comparativo }\end{array}$ & 30 pacientes & $\begin{array}{l}\text { Se colocaron dos mallas de fibrina rica en } \\
\text { plaquetas en el alvéolo correspondiente } \\
\text { al tercer molar inferior izquierdo para } \\
\text { compararlo con el alvéolo del tercer molar } \\
\text { inferior derecho, en donde no se añadió } \\
\text { ninguna sustancia o material biológico } \\
\text { posterior a la extracción dentaria, única- } \\
\text { mente la sutura en puntos simples. }\end{array}$ & $\begin{array}{l}\text { El estudio demostró que la cicatrización } \\
\text { de tejido blando y tejido óseo mejora con } \\
\text { el uso de PRF, afirmando de esta manera } \\
\text { su efectividad. }\end{array}$ \\
\hline $\begin{array}{l}\text { Vento } \\
(2015)\end{array}$ & $\begin{array}{l}\text { Prospectivo, experi- } \\
\text { mental }\end{array}$ & 21 pacientes & $\begin{array}{l}\text { Se realizó este trabajo a boca partida, en } \\
\text { uno de los lados fue el grupo experimen- } \\
\text { tal que recibió el RAR con necesidad de } \\
\text { colgajo más la colocación del PRF en la } \\
\text { zona del defecto y el otro lado fue el grupo } \\
\text { control que solo recibió el RAR con necesi- } \\
\text { dad de colgajo. }\end{array}$ & $\begin{array}{l}\text { El uso del plasma rico en fibrina mejoró } \\
\text { significativamente los parámetros clínicos } \\
\text { gingivales, sangrado, inflamación, además } \\
\text { de la reducción de la profundidad de } \\
\text { sondaje y el nivel de inserción clínico; } \\
\text { comparado con el grupo control }\end{array}$ \\
\hline $\begin{array}{l}\text { Lobatón et al. } \\
(2015)\end{array}$ & $\begin{array}{l}\text { Estudio clínico } \\
\text { comparativo }\end{array}$ & 05 pacientes & $\begin{array}{l}\text { Se les realizó la extracción de ambos } \\
\text { terceros molares, posteriormente se aplicó } \\
\text { la FRP en uno de los lados (lado estudio) } \\
\text { y en el lado contrario no se aplicó ningún } \\
\text { biomaterial (lado control), se evaluó la } \\
\text { cicatrización de las heridas a las } 24 \text { horas, } \\
\text { a los } 7,15,45 \text { días. }\end{array}$ & $\begin{array}{l}\text { Se logró evidenciar que los tejidos blandos } \\
\text { en contacto con la FRP presentaron mejorías } \\
\text { en cuanto al dolor, color, consistencia; } \\
\text { con respecto a las heridas control. Desde } \\
\text { el punto de vista clínico no se observaron } \\
\text { diferencias en cuanto a la disminución del } \\
\text { edema postoperatorio en los pacientes inter- } \\
\text { venidos, por lo tanto la aplicación de la FRP } \\
\text { para este parámetro no fue concluyente. }\end{array}$ \\
\hline $\begin{array}{l}\text { García } \\
(2016)\end{array}$ & $\begin{array}{l}\text { Serie de casos inter- } \\
\text { venidas }\end{array}$ & $\begin{array}{l}\text { En } 11 \text { zonas de } \\
\text { estudio de } 10 \\
\text { pacientes. }\end{array}$ & $\begin{array}{l}\text { Se realizó exodoncia mínimamente trau- } \\
\text { mática y preservación de reborde alveolar } \\
\text { con fibrina rica en plaquetas (PRF) en } \\
\text { dientes que no fuesen rehabilitables. }\end{array}$ & $\begin{array}{l}\text { El uso de fibrina rica en plaquetas como } \\
\text { alternativa para la preservación de rebor- } \\
\text { de alveolar con fines de una implantación } \\
\text { temprana. }\end{array}$ \\
\hline $\begin{array}{l}\text { Atamari et al. } \\
(2017)\end{array}$ & $\begin{array}{l}\text { Cuasi experimental, } \\
\text { longitudinal }\end{array}$ & 18 pacientes & $\begin{array}{l}\text { Se realizó } 2 \text { exodoncias y se colocó fibrina } \\
\text { en un alveolo y el otro alveolo sin fibrina } \\
\text { como sector control, ambos alveolos se } \\
\text { suturaron. }\end{array}$ & $\begin{array}{l}\text { La fibrina rica en plaquetas sí beneficia } \\
\text { el cierre clínico de la mucosa alveolar } \\
\text { postexodoncia, disminuyendo los sínto- } \\
\text { mas y complicaciones post quirúrgicas } \\
\text { y acelerando la cicatrización a los } 7 \text { y } 14 \\
\text { días a diferencia del sector control donde } \\
\text { si hubo presencia de sintomatología post } \\
\text { quirúrgica y lentitud en el cierre clínico. }\end{array}$ \\
\hline $\begin{array}{l}\text { Quispe } \\
\text { (2018) }\end{array}$ & Estudio clínico & 32 alveolos & $\begin{array}{l}\text { Contando con } 16 \text { alveolos para la coloca- } \\
\text { ción de la fibrina rica en plaquetas (grupo } \\
\text { experimental) y } 16 \text { alveolos que no se le } \\
\text { colocó ningún biomaterial (grupo control). } \\
\text { Para la evaluación clínica, se utilizó guías } \\
\text { de acrílico para evaluar pérdida horizontal } \\
\text { y vertical del reborde a los } 2,4 \text { y } 6 \text { meses. } \\
\text { Se tomaron tomografías en el preoperato- } \\
\text { rio y a los } 6 \text { meses, para evaluar ancho y } \\
\text { altura ósea. }\end{array}$ & $\begin{array}{l}\text { A pesar de que la fibrina rica en plaquetas } \\
\text { obtuvo una menor pérdida horizontal y } \\
\text { vertical tanto en los rebordes en la evalua- } \\
\text { ción clínica y tomográfica, la diferencia no } \\
\text { fue significativa entre ambos grupos. Solo } \\
\text { a los } 2 \text { meses de evaluación se obtuvo una } \\
\text { mejor preservación de altura de reborde. }\end{array}$ \\
\hline $\begin{array}{l}\text { Ochoa AI } \\
(2018)\end{array}$ & $\begin{array}{l}\text { Estudio cualitativo } \\
\text { y descriptivo }\end{array}$ & Caso clínico & $\begin{array}{l}\text { Técnica utilizada analítica y sintética, } \\
\text { ayudada por la observación. }\end{array}$ & $\begin{array}{l}\text { Concluyendo que la cirugía resultó exitosa } \\
\text { mediante la aplicación del agregado } \\
\text { plaquetario postexodoncia, es eficien- } \\
\text { te en la regeneración de los tejidos en } \\
\text { corto tiempo, donde no existen molestias } \\
\text { postoperatorias como inflamación y dolor } \\
\text { para el paciente, como sería el caso de una } \\
\text { regeneración natural. }\end{array}$ \\
\hline
\end{tabular}




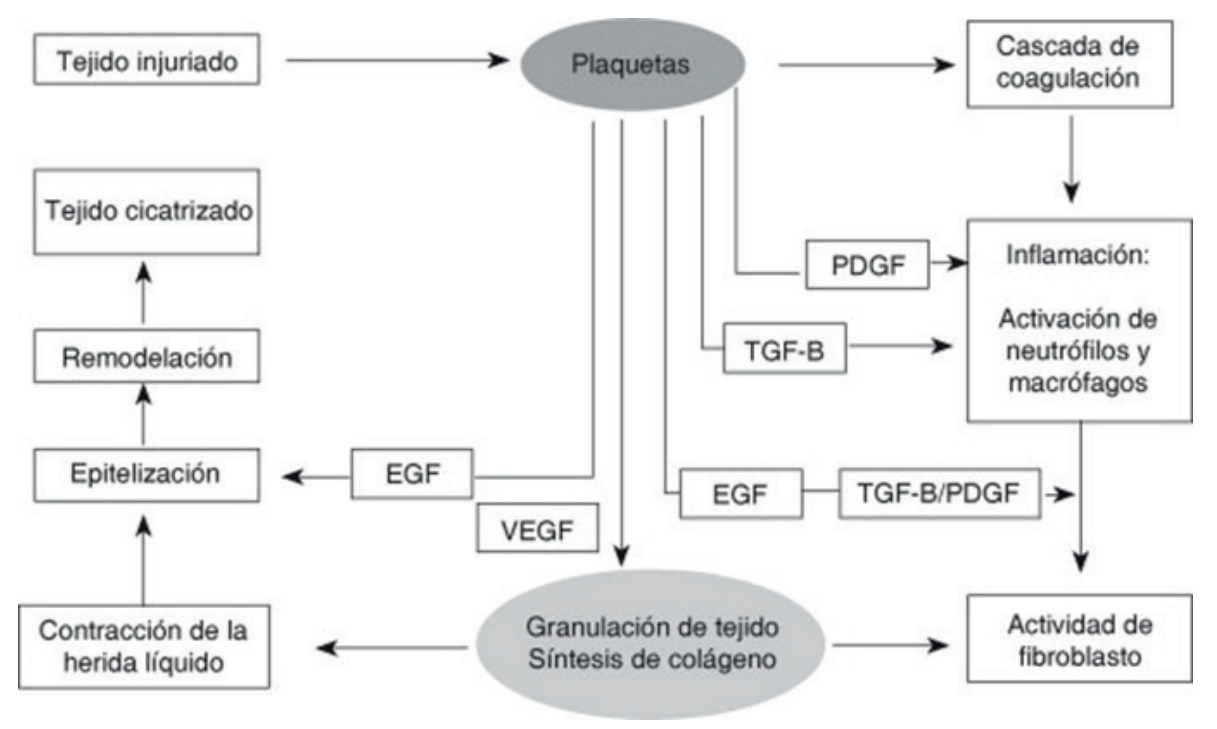

Figura 2. Proceso de cicatrización. Influencia de los factores de crecimiento. Fuente ${ }^{38}$
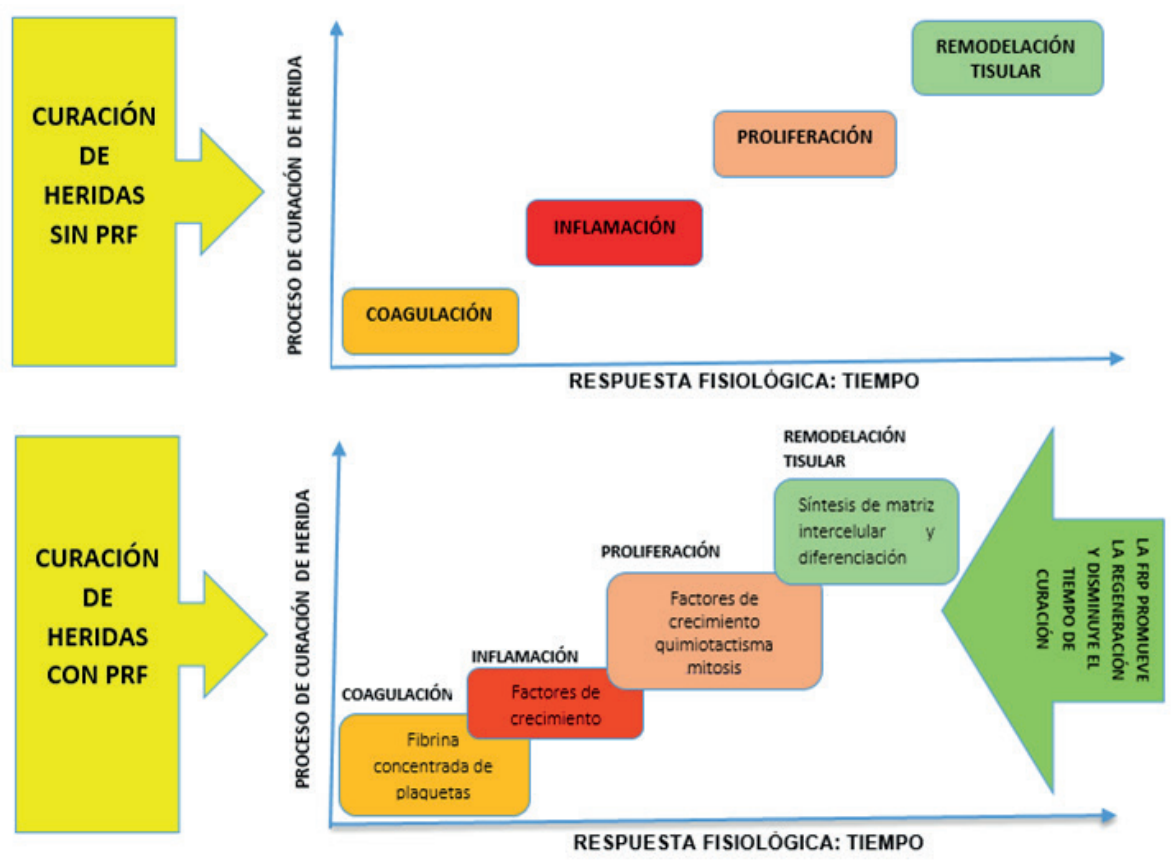

Figura 3. Diagrama del proceso de curación de las heridas en condiciones normales y de su curación acelerada con la aplicación del FRP

y duro mejora con el uso de PRF, demostrando de esta manera su efectividad (Figura 3).

De acuerdo con los estudios realizados se ha demostrado la eficacia de la FRP en regeneración de los tejidos periodontales de pacientes sometidos a cirugías, especialmente en tejidos duros como material de relleno óseo cuando se utilizan injertos ${ }^{42}$. El uso de FRP es altamente predecible en la regeneración ósea y tisular guiada, para contribuir en los mecanismos de regeneración alveolar, elevación y cierres de comunicación del seno maxilar, cierre de fístulas, defectos periodontales, tratamientos de pulpotomía, entre otros ${ }^{43,44}$.

\section{Conclusiones}

Cada vez se conoce más sobre los efectos de la fibrina rica en plaquetas en la regeneración de los tejidos periodontales, pese a haberse promovido su uso ya hace varios ańos por Choukroun es un tema que sigue siendo de mucho interés y la evidencia científica así lo sigue demostrando. Su efecto biológico se sustenta en la viabilidad y proliferación de células para alcanzar la regeneración, promueve la angiogénesis y osteogénesis, la división y diferenciación celular, y la síntesis de colágeno. Por lo tanto, es importante seguir analizando desde diversos puntos de vista la utilidad de este concentrado plaquetario de segunda generación, resaltando sus características: técnica sencilla para obtenerla, bajo costo, origen autógeno, sin aditivos, nula toxicidad no inmunoreactivo; estos lo han llevado a ser considerado 
como una buena alternativa terapéutica frente a otros materiales de regeneración.

\section{Referencias bibliográficas}

1. Gutiérrez R, Infante J, Dávila L, Sosa L, Jerez E. Cicatrización periodontal: Revisión de la literatura. Acta Bioclínica. 2018;8(15):249-55.

2. Atamari VK, Sanga C, Huayhua KY. Fibrina rica en plaquetas en el cierre clínico de la mucosa alveolar post-exodoncia en pacientes sometidos a cirugía bucal. Revista Evidencias en Odontología Clínica. [Publicación en línea] diciembre 2017. [Citado 2019 junio 23]; 3(2). Disponible en: https://revistas.uancv.edu.pe/index.php/ EOC/article/view/494.

3. Sculean A, Gruber R, Bosshardt DD. Cicatrización y regeneración periodontal. Revista Seleccionado. 2014;24(2):131-136.

4. Shobha P, Aditi T. Platelet Concentrate: Past, Present and Future. J Maxillofac Oral Surg. 2011;10(1):45-49.

5. Bhanot S, Alex JC. Current applications of platelet gels in facial plastic surgery. Facial Plast Surg. 2002;18:27-33.

6. Toffler M, Toscano N, Holtzclaw D, Corso MD, Dohan Ehrenfest D. Introducing Choukroun's platelet rich fibrin (PRF) to the reconstructive surgery milieu. J Implant Adv Clin Dent. 2009;1(6):21-30.

7. Montanari M, Callea M, Yavuz I, Maglione M. A new biological approach to guided bone and tissue regeneration. BMJ. 2013;9(2):1-3.

8. Meza EJ, Lecca MP, Correa E, Ríos K. Fibrina rica en plaquetas y su aplicación en periodoncia: revisión de literatura. Rev Estomatol Herediana. 2014;24(4):287-293.

9. Manual de Procedimientos Estandarizados para la Vigilancia Epidemiológica de las Patologías Bucales [en línea]. México: Dirección General de Epidemiología; 2012. [citado 2019 julio 26]. Disponible:http://www. cenaprece.salud.gob.mx/programas/interior/saludbucal/ descargas/pdf/20_2012_Manual_PatBucales_vFinal.pdf

10. Fabrizi S, Barbieri G, Vignoletti F, Bascones-Martínez A. Tratamiento quirúrgico vs terapia periodontal básica: estudios longitudinales en periodoncia clínica. Av Periodon Implantol. 2007;19(2):161-175.

11. Matos R, Bascones-Martinez A. Tratamiento periodontal quirúrgico: Revisión. Conceptos. Consideraciones. Procedimientos. Técnicas. Av Periodon Implantol. 2011;23(3):155-170.

12. Garay AE, Altuve CA, Castillo AJ, González JY. Plasma rico en plaquetas en la cicatrización de los tejidos blandos de la cavidad bucal. Acta Bioclínica. 2014;4(7):66-84.

13. Khiste SV, Tari RN. Platelet-rich fibrin as a biofuel for tissue regeneration. ISRN Biomaterials. 2013; 2013:1-6. DOI: http://dx.doi.org/10.5402/2013/627367.

14. Guarín C, Quiroga P, Landinez NS. Proceso de Cicatrización de heridas de piel, campos endógenos y su relación con las heridas crónicas. Rev Fac Med. 2013;61(4):441448 .

15. Rodríguez J, Palomar MA, Torres-García J. Plasma Rico en Plaquetas: Fundamentos biológicos y aplicaciones en cirugía maxilofacial y estética facial. Rev Esp Cir Oral Maxilofac. 2012;34(1):8-17.

16. Dohan DM, Choukroun J, Diss A, et al. Platelet-rich fibrin (PRF): A second-generation platelet concentrate; Part I: Technological concepts and evolution. Oral Surg Oral Med Oral Pathol Oral Radiol Endod. 2006;101:3744.

17. Salgado-Filho I, Zanini AS, Mélega JM, Zanini SA, Psillakis JM. Reparação dos traumas de pele e tecidos moles. In: Cirugía plástica reparadora y estética. Rio de Janeiro: Medsi; 1992;139-45.

18. Gassling VL, Açil Y, Springer IN, Hubert N, Wiltfang J. Platelet-rich plasma and platelet-rich fibrin in human cell culture. Oral Surg Oral Med Oral Pathol Oral Radiol Endod. 2009;108:48-55.

19. Jameson C. Autologus Platelet Concentrate for the production of Platelet Gel. LABMEDICINE. 2007;38(1): 39-42. DOI: http://dx.doi.org/10.1309/3UA5HWYVKNCE01AR.

20. Di Pascua M. Concentrados plaquetarios. Tendencias en Medicina. 2017;26(50):125-132.

21. Escalente W, Castro G, Geraldo L, Carlos M. Fibrina Rica en Plaquetas (FRP): Una alternativa terapéutica en odontología. Rev. Estomatol Herediana. 2016;26(3):173-8.

22. Gupta V, Bains BK, Singh GP, Mathur A, Bains R. Regenerative potential of platelet rich fibrin in dentistry: Literature review. Asian J Oral Health Allied Sci. 2011;1:22-28.

23. García V, Corral I, Bascones A. Plasma rico en plaquetas y su utilización en implantología dental. Av Periodon Implantol. 2004;16(2):81-92.

24. Yanez B, Marin M. Tratamiento de periodontitis agresiva localizada con plasma rico en plaquetas y aloinjerto óseo. Un caso clínico. Rev. Odon. Mex. 2015;19(2):106-114.

25. Mosesson MW, Siebenlist KR, Meh DA. The structure and biological features of fibrinogen and fibrin. Ann N Y Acad Sci. 2001;936:11-30.

26. Gassling V, Açil Y, Springer I, Hubert N, Wiltfang J. Platelet-rich plasma and platelet-rich fibrin in human cell culture. Oral Surg Oral Med Oral Pathol Oral Radiol Endod. 2009;108:48-55.

27. Grey RG. Fibrin as a hemostatic in cerebral surgery Surg Gynecol Obstet. 1915;21:452-454.

28. Gutiérrez DA, Hinojosa JP, Restrepo AI, Muñoz AL, Velarde NF, Bastidas FE. Análisis estructural de la fibrina rica en plaquetas y sus aplicaciones en odontología regenerativa. Univ Odontol. 2018;37(79). DOI: 10.11144/ Javeriana.uo37-79.aefr.

29. Sunitha V, Munirathnam E. Platelet-rich fibrin: Evolution of a second-generation platelet concentrate. Indian J Dent Res. 2008;19(7):42-46.

30. Tovar JL. Aplicación de fibrina rica en plaquetas en la cicatrización y regeneración postexodoncias dentarias en pacientes con riesgo y con osteonecrosis maxilar inducida por bifosfonatos. [Trabajo especial de Grado]. Caracas: Universidad Central de Venezuela. Facultad de Odontología Postgrado de Cirugía Bucal. 2011. 
31. Lobo N. Evaluación clínica del tiempo de cicatrización de alvéolos post extracción, aplicando distintas técnicas de cierre de heridas. [Tesis para optar el título de Cirujano Dentista]. Santiago de Chile: Universidad Andrés Bello. Facultad de Odontología. 2014.

32. Vento DE. Efecto clínico del plasma rico en fibrina (PRF) como terapia conjunta a la fase quirúrgica en el tratamiento de la periodontitis crónica. [Tesis para optar el Título Profesional de Cirujano Dentista]. Lima: Universidad Nacional Mayor de San Marcos. Facultad de Odontología. E.A.P. de Odontología. 2015.

33. Lobatón A. Efecto de la fibrina rica en plaquetas para la cicatrización de tejidos blandos post - exodoncia de terceros molares inferiores retenidos. [Tesis para aprobar el Diplomado de Odontología]. Mérida: Universidad de los Andes. Facultad de Odontología. 2015.

34. García LC. Uso de PRF (fibrina rica en plaquetas) en preservación de reborde alveolar. estudio clínico descriptivo. [Tesis para optar el título de Especialista en Periodoncia]. Bogotá: Universidad Nacional de Colombia. Facultad de Odontología. 2016.

35. Quispe MD. Efecto del uso de la fibrina rica en plaquetas, según el protocolo de Choukroun, como único material en la preservación del reborde alveolar post-exodoncia. [Tesis para optar el Título Profesional de Cirujano Dentista]. Lima: Universidad Nacional Mayor de San Marcos. Facultad de Odontología. E.A.P. de Odontología. 2018.

36. Ochoa AI. Proceso de cicatrización post exodoncia de los terceros molares mandibulares mediante la utilización de plasma rico en plaquetas. [Tesis de grado]. Guayaquil: Universidad Estatal de Guayaquil. Facultad piloto de Odontología. 2018.

37. Ross R, Glomset J, Kariya B, Harker L. A plateletdependent serum factor that stimulates the proliferation of arterial smooth muscle cells in vitro. Proc Natl Acad Sci USA. 1974;71:1207-10. https://www.researchgate.net/profile/Angel_Orion_Salgado-Peralvo/publication/311963010.
38. Yáñez BR, Marín MG. Tratamiento de periodontitis agresiva localizada con plasma rico en plaquetas y aloinjerto óseo. Un caso clínico. Rev Odont Mex. 2015;19(2):106-114

39. Choukroun J. Choukroun's fibrina rica en plaquetas puede usarse en diversas especialidades de odontología. Lima, Perú: Universidad Nacional Mayor de San Marcos; 2014.

40. Hernández I, Rossani G, Alcolea JM, Castro-Sierra R, Pérez W, Trelles MA. Utilidad práctica de la fibrina autóloga en medicina reparadora y cirugía plástica. Cirugía Plástica Ibero-latinoamericana. 2014;40(3):345-57.

41. Guzmán GF, Paltas ME, Benenaula JA, Núñez KI, Simbaña DV. Cicatrización de tejido óseo y gingival en cirugías de terceros molares inferiores. Estudio comparativo entre el uso de fibrina rica en plaquetas versus cicatrización fisiológica. Rev Odont Mex. 2017;21(2):114-120.

42. Arce MA, Díaz AM, Díaz M, Hernández VJ. Fibrina rica en plaquetas y leucocitos: biomaterial autólogo excelente para regeneración tisular. Medicentro Electrónica. 2018;22(1):19-26.

43. Cid FA. Eficacia del plasma rico en plaquetas y la fibrina rica en plaquetas en la regeneración periodontal: revisión sistemática. Int. J. Med. Surg. Sci. 2017;4(3):1196-1202.

44. Lobatón A, Mantilla A, Felzani R, Suárez D, González A. Efecto de la fibrina rica en plaquetas para la cicatrización de tejidos blandos post - exodoncia de terceros molares inferiores retenidos. Acta Odontol Venez. 2015;53(3):3-11.

45. Castro AB, Meschi N, Temmerman A, et al. Regenerative potential of Leucocyte- and Platelet Rich Fibrin (L-PRF). Part A: intrabony defects, furcation defects, and periodontal plastic surgery. A systematic review and meta-analysis. J Clin Periodontol. 2016;44:67-82. 